\title{
Microspheres for the Growth of Silicon Nanowires via Vapor-Liquid-Solid Mechanism
}

\author{
Arancha Gómez-Martínez, ${ }^{1}$ Francisco Márquez, ${ }^{2}$ Eduardo Elizalde, ${ }^{1}$ and Carmen Morant ${ }^{1}$ \\ ${ }^{1}$ Departamento de Física Aplicada and Instituto de Materiales Nicolás Cabrera, Universidad Autónoma de Madrid, \\ Cantoblanco, 28049 Madrid, Spain \\ ${ }^{2}$ School of Science and Technology, University of Turabo, Gurabo, PR 00778, USA
}

Correspondence should be addressed to Arancha Gómez-Martínez; arancha.gomez@uam.es

Received 29 October 2013; Accepted 12 January 2014; Published 19 February 2014

Academic Editor: José María Sanz

Copyright (C) 2014 Arancha Gómez-Martínez et al. This is an open access article distributed under the Creative Commons Attribution License, which permits unrestricted use, distribution, and reproduction in any medium, provided the original work is properly cited.

Silicon nanowires have been synthesized by a simple process using a suitable support containing silica and carbon microspheres. Nanowires were grown by thermal chemical vapor deposition via a vapor-liquid-solid mechanism with only the substrate as silicon source. The curved surface of the microsized spheres allows arranging the gold catalyst as nanoparticles with appropriate dimensions to catalyze the growth of nanowires. The resulting material is composed of the microspheres with the silicon nanowires attached on their surface.

\section{Introduction}

Silicon nanowires (SiNWs) have recently gained great interest as an alternative to carbon materials as carbon nanotubes or graphene. Silicon is one of the most common materials in the crust of the Earth ( 90\%) and its acquisition, processing, and application in the technological industry is well known [1]. One-dimensional silicon structures are particularly attractive because of their mechanical, optical, and electrical properties. Nowadays, a number of applications are being investigated for such SiNWs, including intensive blue light emitters in integrated optics [2], field effect transistors [3], and sensor applications $[4,5]$. There is also growing interest in the use of SiNWs in energy storage devices, in particular as active material for the anode of lithium ion batteries $[6,7]$ because silicon has the highest known theoretical specific capacity (higher than $4200 \mathrm{~mA} \mathrm{~h} / \mathrm{g}$ ).

Silicon nanowires with the characteristics described above have been synthesized using various methods including chemical vapor deposition (CVD) $[8,9]$, laser ablation [10], colloidal solution [11], and arc-discharge [12]. The growth mechanism in all of these techniques is explained by the vapor-liquid-solid (VLS) model, described for the first time by Wagner and Ellis [13]. They reported that silicon whiskers could be grown from metal impurities following a catalytic process. The role of impurity was to form a liquid solution for the vapor-phase adsorption of $\mathrm{Si}$ atoms until solution became supersaturated and subsequently silicon nanowire started to form from the liquid metal/semiconductor interface. Nowadays, some new research, including this which has been conducted in our group [14], synthesizes these nanowires by the same process but using a solid silicon source instead of a gaseous silicon source [15-17].

In the present work, the synthesis of SiNWs has been carried out by a thermal treatment process by using the substrate as solid Si source. This silicon substrate was covered by microsized spheres in order to promote the growth of $\mathrm{Si}$ nanowires.

\section{Materials and Methods}

2.1. Chemicals and Materials. All reagents used in the present study were of analytical grade. Ammonia (30\%) and ethanol absolute (99.8\%) were provided by Panreac Química S.A. Tetraethyl orthosilicate (TEOS, $\left.\left(\mathrm{Si}_{(}\left(\mathrm{C}_{2} \mathrm{H}_{5} \mathrm{O}\right)_{4}\right), \geq 99.0 \%\right)$ was 
TABLE 1: Synthesis parameters of silica microspheres.

\begin{tabular}{llc}
\hline Sample & Synthesis parameters & $\begin{array}{c}\text { Average } \\
\text { diameter } \\
(\mathrm{nm})\end{array}$ \\
\hline S1 & DDW: $1.30 \mathrm{~mL} ; \mathrm{NH}_{3}: 3.66 \mathrm{~mL}$; EtOH: $28.86 \mathrm{~mL}$ & 800 \\
S2 & DDW: $0.65 \mathrm{~mL} ; \mathrm{NH}_{3}: 3.66 \mathrm{~mL} ; \mathrm{EtOH}: 30.15 \mathrm{~mL}$ & 750 \\
S3 & DDW: $0 \mathrm{~mL} ; \mathrm{NH}_{3}: 3.66 \mathrm{~mL} ; \mathrm{EtOH}: 15 \mathrm{~mL}$ & 100 \\
S4 & DDW: $0 \mathrm{~mL} ; \mathrm{NH}_{3}: 2 \mathrm{~mL} ; \mathrm{EtOH}: 15 \mathrm{~mL}$ & 50 \\
\hline
\end{tabular}

TABLE 2: Synthesis parameters of carbon microspheres.

\begin{tabular}{lcc}
\hline Sample & Concentration $(\mathrm{M})$ & Average diameter $(\mathrm{nm})$ \\
\hline $\mathrm{C} 1$ & 1.5 & 8000 \\
$\mathrm{C} 2$ & 0.3 & 2000 \\
$\mathrm{C} 3$ & 0.08 & 200 \\
$\mathrm{C} 4$ & 0.05 & 80 \\
\hline
\end{tabular}

provided by Aldrich Chemical Co. The carbohydrate compound used for the synthesis of carbon microspheres was commercial sucrose. Ultrapure water (DDW, Milli-Q water, $18.2 \mathrm{M} \Omega \mathrm{cm}$ at $25^{\circ} \mathrm{C}$ ) was used in all experiments. The substrate of all experiments was silicon (100) wafer p-type, boron doped.

\subsection{Synthesis of Microspheres}

$\mathrm{SiO}_{2}$ Microspheres. Silica microspheres were synthesized following the method described by Stöber et al. [18], slightly modified to obtain materials with larger specific surface area [19]. This method consists of the hydrolysis of TEOS in ethanol in the presence of ammonia as a catalyst. This reaction is made in ultrapure water. With the aim of obtain obtaining particles with lower diameters, the reaction was done at $50^{\circ} \mathrm{C}$ under constant stirring. After one hour of reaction, the shape and size of the silica microspheres in solution were completely defined. The obtained spheres have diameters, as determined by FESEM images, ranging from ca. $50 \mathrm{~nm}$ to $800 \mathrm{~nm}$, depending on the experimental conditions (Table 1).

Carbon Microspheres. Carbon microspheres were synthesized according to the method described by Wang et al. [20], consisting in a dehydration and subsequent condensation of sucrose. Aqueous sucrose solutions with different concentrations (Table 2) were introduced in Teflon-lined stainless steel autoclaves, for hydrothermal synthesis. Autoclaves were placed in an oven at $190^{\circ} \mathrm{C}$ for 5 hours.

The reaction product was filtered and washed with water and ethanol and then dried in an oven at $50^{\circ} \mathrm{C}$ for several hours. Next, the as-grown carbon microspheres were subsequently graphitized in a tubular quartz furnace in flowing $\mathrm{Ar}$

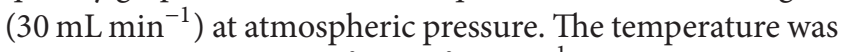
ramped from 30 to $1000^{\circ} \mathrm{C}$ at $5^{\circ} \mathrm{C} \mathrm{min}^{-1}$. After dwelling for 10 minutes, the samples were ramped down at $30^{\circ} \mathrm{C} \mathrm{min}^{-1}$ to room temperature. The resultant powder was composed of aggregates of well-defined shape carbon microspheres.
For their subsequent use, microspheres were suspended in ethanol at $10 \mathrm{mg} \mathrm{mL}^{-1}$.

2.3. Synthesis of Silicon Nanowires. Silicon nanowires were synthesized by chemical vapor deposition at $900^{\circ} \mathrm{C}$ according to the VLS growth mechanism using Au as catalyst. Details of this method have previously been reported [14]. Single fragments of $\mathrm{Si}(100)$ coated with silica or carbon microspheres were used as substrates.

Microspheres were deposited on the silicon substrate by dip coating. Subsequently, a thin film of gold $(10 \mathrm{~nm}$ thick) was deposited by sputtering (Sputter Coater SC502). Samples were heated at $900^{\circ} \mathrm{C}$ in a tubular quartz furnace at atmospheric pressure in flowing a mixture of $\mathrm{H}_{2}$ and $\operatorname{Ar}(3: 1)$ during $30 \mathrm{~min}$ with a heating rate of $25^{\circ} \mathrm{C} \mathrm{min}^{-1}$.

With the aim of characterizing the gold nanoparticles obtained by thermal processing, an additional treatment was done with the same parameters but in absence of hydrogen, which allows the generation of nanoparticles but not the formation of the nanowires.

2.4. Characterization. Field-emission scanning electron microscopy (FE-SEM, Philips XL30 S-FEG) was used to characterize the nanowires and microspheres, as well as the formation of gold nanoparticles after the synthesis without hydrogen.

The structure of the SiNWs was examined by high resolution transmission electron microscopy (HRTEM, JEOL JEM $3000 \mathrm{~F}$ ) operated at $300 \mathrm{kV}$. SiNWs previously grown were peeled off from the substrate surface and dispersed in a beaker containing ethanol by ultrasonication. The HRTEM samples were prepared by adding several drops of this solution onto a standard copper grid. Their chemical composition was analyzed with energy dispersive X-ray spectroscopy (EDS, OXFORD INCA) integrated in this system.

X-ray photoelectron spectroscopy measurements were performed on a PHI 3027 spectrometer with a nonmonochromatic $\mathrm{Mg} \mathrm{K} \alpha(1253.6 \mathrm{eV})$ radiation of a twin anode in the constant analyzer energy mode with a pass energy of $50 \mathrm{eV}$. In order to obtain the stoichiometric composition of the nanowires, dispersed nanowires in ethanol were deposited on a highly oriented pyrolytic graphite (HOPG) substrate for the subsequent XPS analysis.

\section{Results and Discussion}

It has been reported $[21,22]$ that when a polished silicon substrate is covered with a thin gold layer of a few nanometers thick and heated in the adequate atmosphere at a temperature above the eutectic Au-Si temperature, gold melts and diffuses into bulk silicon exhibiting a crack pattern. In this process, the gold gives rise to large microparticles composed of a silicongold alloy. Figure 1 shows the FESEM images of the crack pattern produced by $10 \mathrm{~nm}$ of gold deposited on the silicon (100) surface that has been subjected to a thermal treatment at $900^{\circ} \mathrm{C}$ in $\mathrm{H}_{2}$ and Ar atmosphere. The large dimensions of the gold particles formed do not allow their catalytic role for the SiNWs growth. 


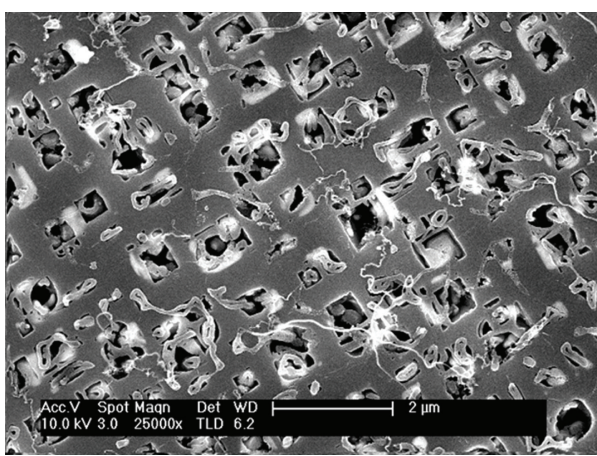

(a)

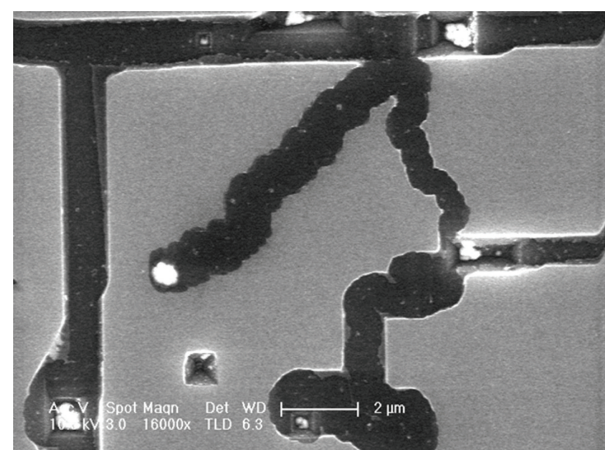

(b)

Figure 1: FESEM images of the polished $\mathrm{Si}(100)$ surface covered by $10 \mathrm{~nm}$ of $\mathrm{Au}$, after the CVD process $\left(900^{\circ} \mathrm{C}, \mathrm{H}_{2}\right.$ and $\mathrm{Ar}$ atmosphere), showing the cracks (a) and paths (b) formed.

Several methods have been described to achieve the adequate size of the Au nanoparticles to obtain SiNWs. Most of these methods require a previous modification of the substrates surfaces, either by chemical or physical etching, the use of masks or by lithography, making the process more complex. A different option is the addition of suitable nanomaterials on the silicon substrate in order to find an adequate surface on which gold layer gives rise to nanoparticles small enough to catalyze the SiNWs growth. In this work, silica and carbon microspheres were used as coverage of the substrate to allow the generation of adequate catalyst gold nanoparticles for the subsequent growth of SiNWs.

The process of generation of droplets and growth of nanowires during the thermal treatment, by using microspheres as supporting material, is schematically described in Figure 2. The thin layer of gold, deposited by sputtering on the silicon surface covered with the microspheres, forms halfshells on each microsphere. These half-shells become, during thermal treatment, in droplets relatively uniform in shape and size. These droplets have the adequate size to catalyze the SiNWs growth. The Si is incorporated into the droplets until the alloy becomes supersaturated, promoting the growth of the nanowires. If the thickness of the gold layer is fixed, the size of gold droplets could be controlled by varying the diameter of the microspheres.

In order to study the initial state of the gold nanoparticles and to confirm the requirement of the curved surface of the microspheres for the formation of gold catalyst droplets, a supplementary thermal treatment was performed without the incorporation of $\mathrm{H}_{2}$ gas. In this way, it was possible to control the formation of gold nanoparticles since the SiNWs growth is avoided in this specific thermal treatment, but nevertheless, the gold nanoparticles were formed. The FESEM images of silica spheres (Figure 3(a)) and carbon spheres (Figure 3(b)) deposited on Si (100), covered with gold, after the thermal treatment at $900^{\circ} \mathrm{C}$ (without $\mathrm{H}_{2}$ ), clearly show the dimensions and specific location of the Au nanoparticles, corresponding to the brightest points of the images.

After the analysis of the experimental results, it can be concluded that there is an upper limit for the diameter of the microspheres (around $1 \mu \mathrm{m}$ ) above which the gold halfshell, initially located on top of each sphere (Figure 2(b)), is segregated into several particles during heating, larger on the top and smaller on the edge. In order to show both situations, silica spheres with diameters lower than $1 \mu \mathrm{m}$ and carbon spheres with diameters larger than $1 \mu \mathrm{m}$, were used. Figure 3 shows a general view of the samples covered with the gold particles. The difference in size when small silica particles or large carbon spheres are used is responsible for a different distribution of gold nanoparticles over their surfaces. As a result, a main gold particle (ca. $140 \mathrm{~nm}$ diameter) remains on each sphere in the case of using silica particles as substrate (Figure 3(a)), and larger gold particles (ca. $500 \mathrm{~nm}$ diameter) can be observed on top of the sphere surrounded by smaller nanoparticles around it when carbon spheres are used as substrate (Figure 3(b)).

During the thermal reaction with $\mathrm{H}_{2}$ and Ar, gold particles adsorb silicon atoms coming from the surface until solution becomes supersaturated and silicon nanowires start to form. A scheme of the process is shown in Figure 2(d). It might be expected that a homogeneous distribution of the microspheres could favor a higher density of SiNWs, because the $\mathrm{Si}$ source could be more accessible to the catalyst. This explanation is corroborated in Figure 4(a), where a large density of nanowires covers almost entirely the silica spheres. However, in Figure 4(b), due to the unequal distribution of the gold particles, there are some bare regions, so that the nanowires are only generated from the surrounding areas of the carbon spheres.

An extensive analysis of the FESEM images was carried out in order to quantify the diameter distribution of the spheres, the catalyst gold particles, and the nanowires grown. Histograms of the results, for both silica and carbon spheres, are presented in Figure 5. Figure 5(I) shows that silica spheres with diameters of $780 \pm 20 \mathrm{~nm}$ give rise to gold particles with diameters of $140 \pm 10 \mathrm{~nm}$. Such estimations only take into account the main particle over each sphere. The SiNWs obtained from these particles had average diameters of $40 \pm$ $10 \mathrm{~nm}$. On the other hand, Figure 5(II) shows that carbon spheres with diameters of $8 \pm 1 \mu \mathrm{m}$ give rise to gold particles 


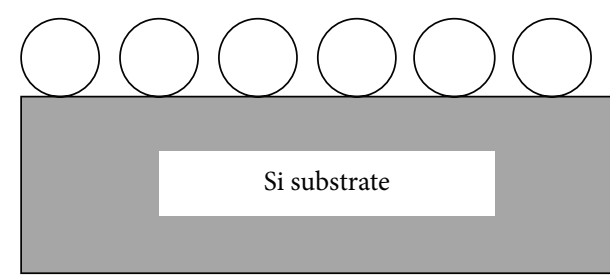

(a)

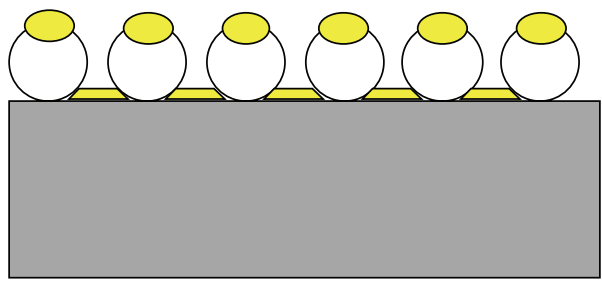

(c)

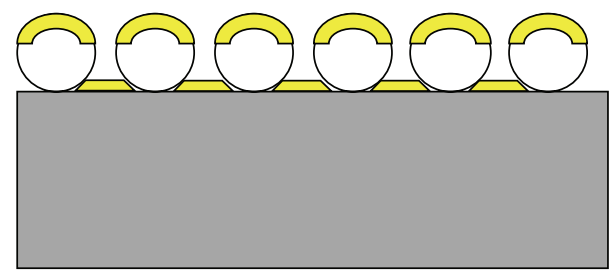

(b)

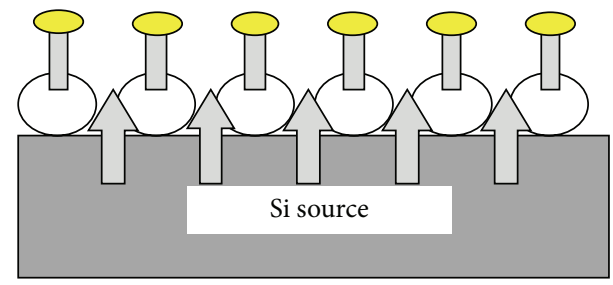

(d)

FIGURE 2: Schematic representation of the mechanism of SiNWs growth by VLS: (a) deposition of microspheres on Si surface; (b) deposition of a thin layer of $\mathrm{Au}$; (c) formation of gold droplets on the top of the microspheres; (d) incorporation of Si into droplets, supersaturation, and growth of nanowires.

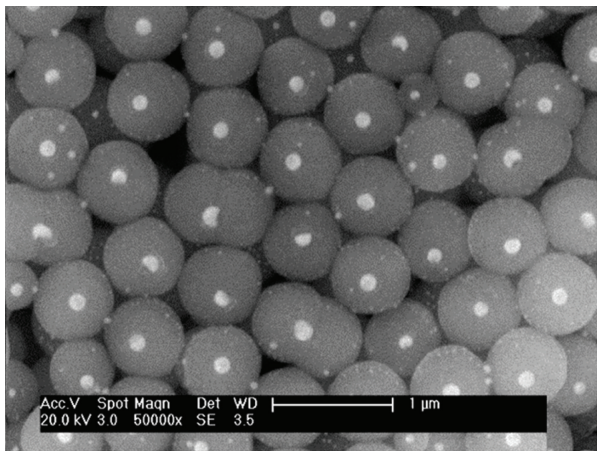

(a)

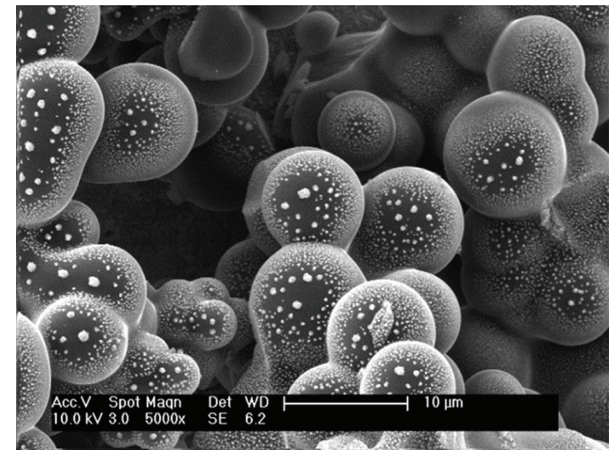

(b)

FIGURE 3: FESEM images of gold nanoparticles synthesized on Au/silica spheres/Si (a) and on Au/carbon spheres/Si (b), after thermal treatment at $900^{\circ} \mathrm{C}$ without $\mathrm{H}_{2}$.

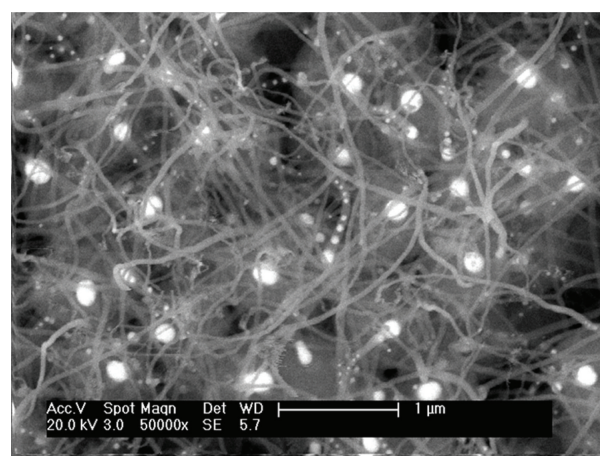

(a)

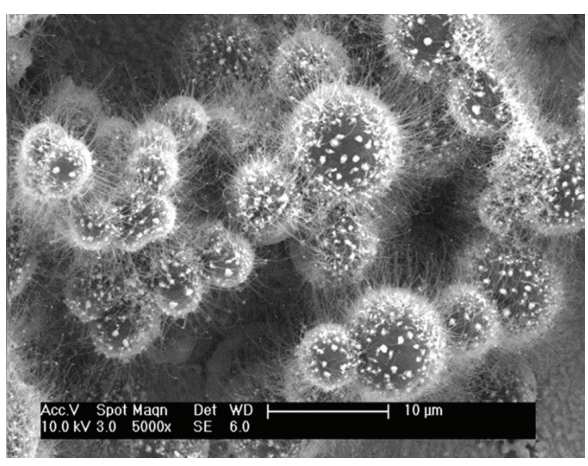

(b)

FIGURE 4: FESEM images of Si nanowires grown on $\mathrm{Au} /$ silica spheres/Si (a) and on $\mathrm{Au} /$ carbon spheres/Si (b), after reaction at $900^{\circ} \mathrm{C}$ in flowing hydrogen. 

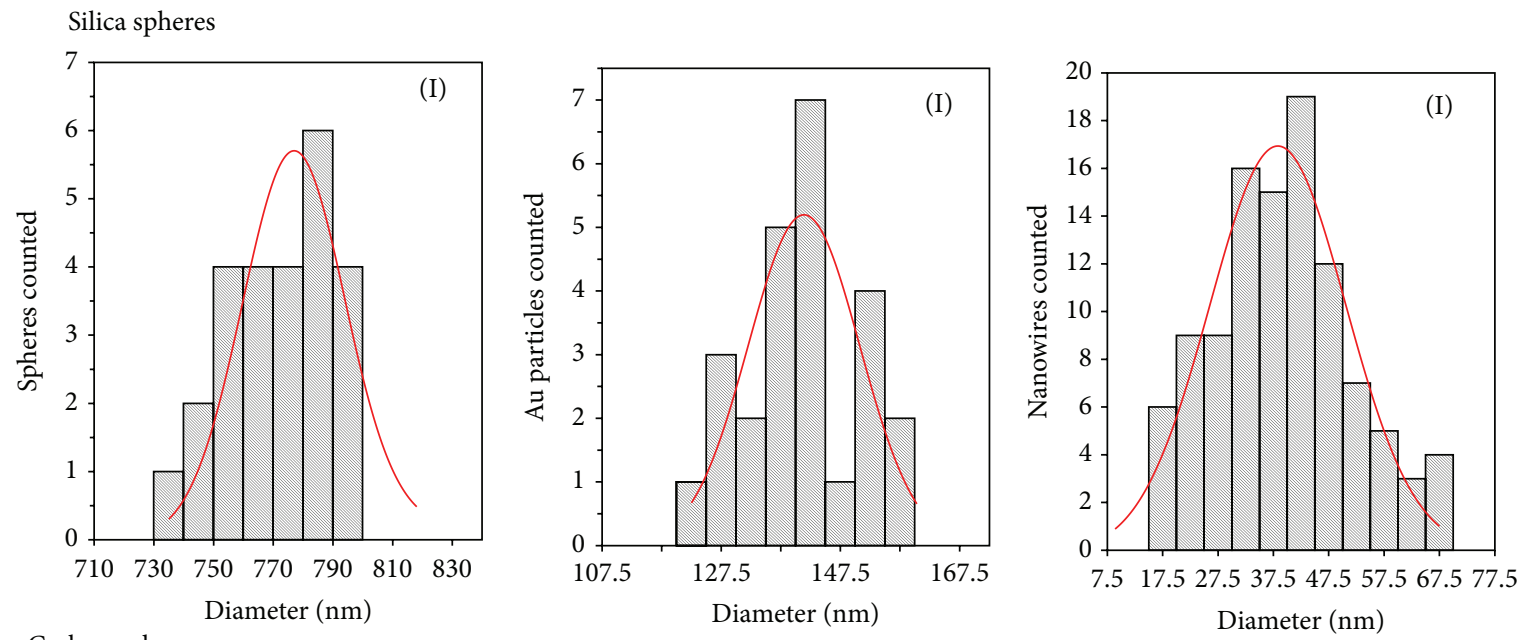

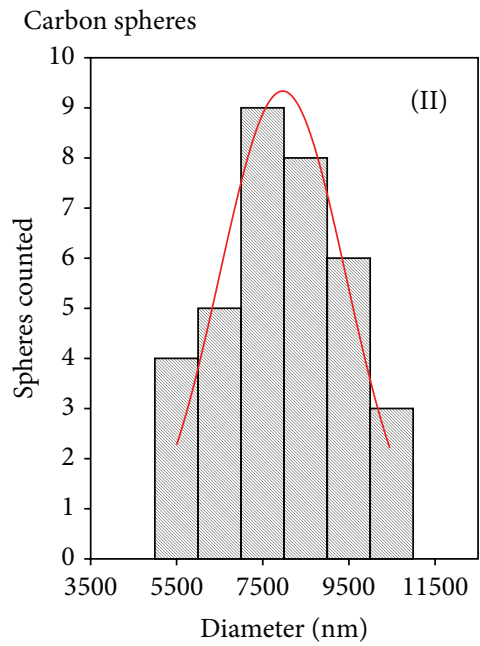

(a)

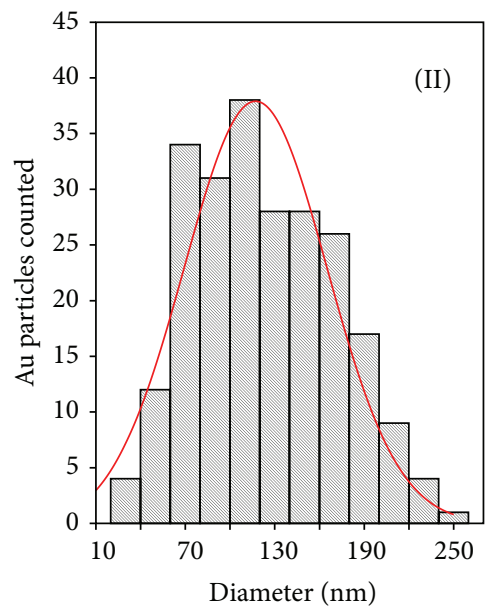

(b)

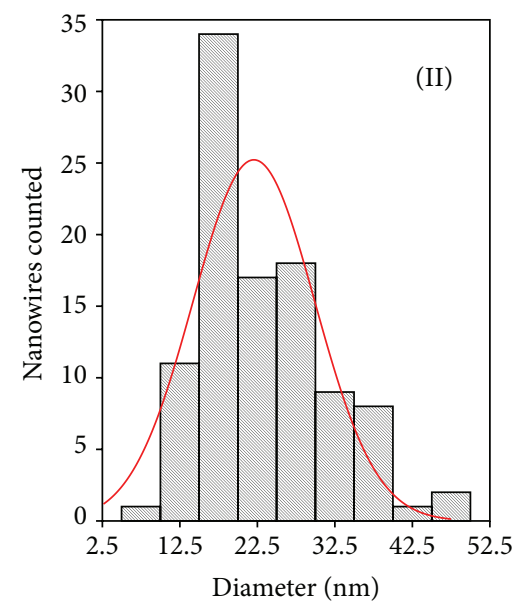

(c)

Figure 5: Histograms, obtained from FESEM images, corresponding to the diameters of (a) silica and carbon spheres; (b) gold particles generated on their surface; and (c) SiNWs. The red smooth curves show the Gaussian fit of the distributions.

of $120 \pm 50 \mathrm{~nm}$ diameter. In these histograms, the large particles on the top of the spheres, with diameters around $500 \mathrm{~nm}$, have been excluded because they do not contribute to the growth of nanowires. The SiNWs grown from the rest of gold particles on carbon spheres had an average diameter of $22 \pm 8 \mathrm{~nm}$.

Considering the margin of error of this study, the use of small spheres (diameters lower than $1 \mu \mathrm{m}$ ) enables a better control of the catalyst particle size than using larger spheres. For small spheres, the gold particle size only depends on the thickness of the gold layer and the diameter of the sphere. In the case of large spheres, additional parameters, including the surface tension between the gold layer and the carbon spheres or even the curvature and roughness of the sphere, should be considered. This explains that the distribution of the particle size appears more homogeneous for small silica than for large carbon spheres.

With respect to the SiNWs, and according to the VLS mechanism, the synthesized nanowires have the same diameter as the catalyst particle. However, the results obtained in this research show that the SiNWs are characterized by having lower diameters that those expected by the particles sizes. The reason is probably due to the fact that only a fraction of the gold particle is responsible for the nanowires growth. This can be observed in the TEM image of a nanowire (Figure 6(a)) that shows how the initial gold particle has been decomposed into several small particles along the nanowires and at the tip (Figure 6(b)).

The high resolution image of Figure 6(c) shows the crystalline structure of the gold particle on the tip of the nanowire. Nanowires, however, were amorphous according to Figure 6(d), which is consistent with the presence of oxygen in the nanowire composition, as measured by EDX and XPS.

Figure 7(a) shows the TEM image of a single Si nanowire with its corresponding EDX spectrum. The EDX analysis indicated the presence of $\mathrm{Si}, \mathrm{O}, \mathrm{C}$, and $\mathrm{Cu}$. Small amounts of carbon and copper peak were attributed to the background signal of the support grid where SiNWs were deposited. The oxygen detected was assigned to the contribution of 

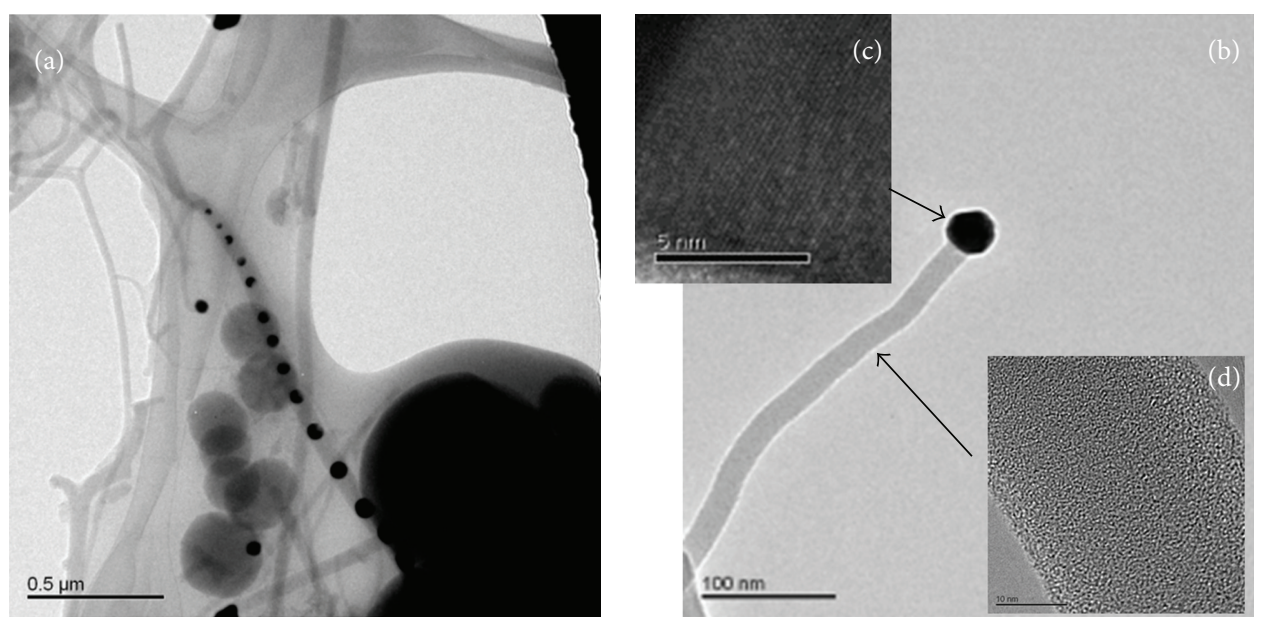

FIGURE 6: HRTEM images of (a) some SiNWs growing from silica spheres, (b) a gold particle at the tip of one of them, and a nearer views of (c) the gold particle and (d) the nanowire.

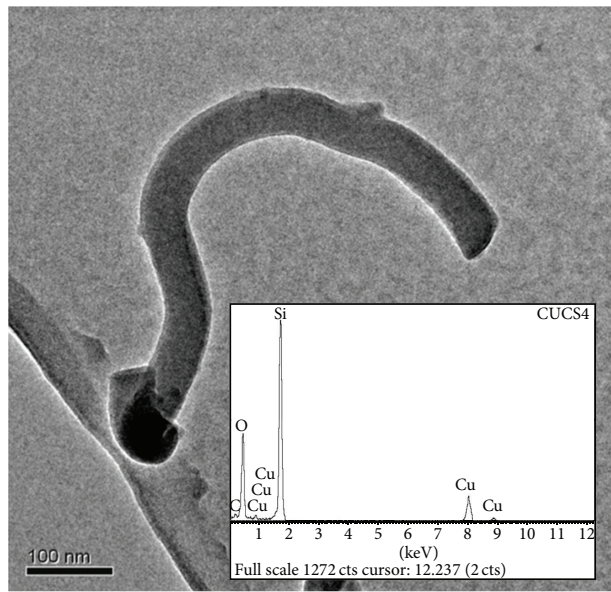

(a)

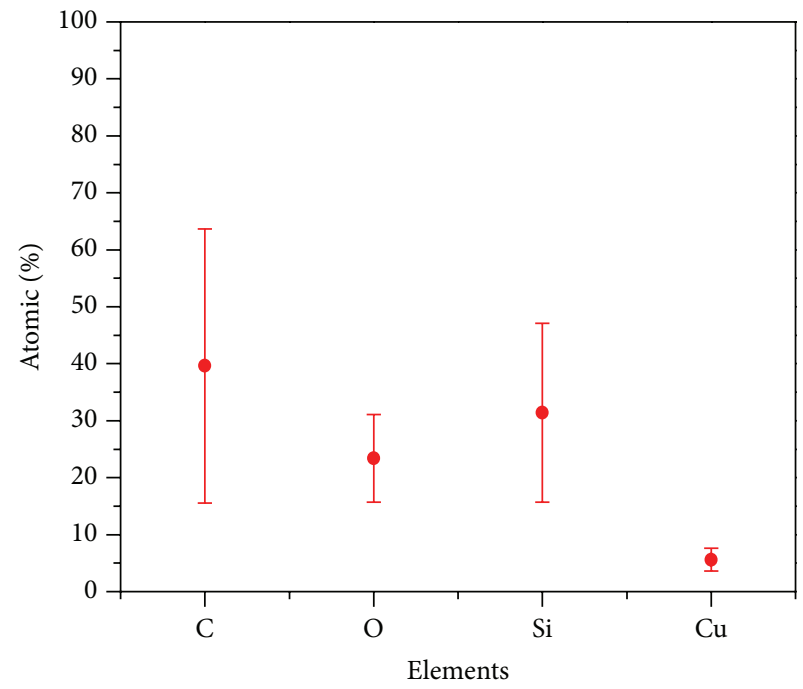

(b)

FIGURE 7: (a) HRTEM image and EDX spectrum of a single nanowire and (b) atomic composition obtained from the EDX spectra of the SiNWs.

oxidized SiNWs and possible contamination (binding to $\mathrm{Cu}$ and $\mathrm{C}$ ). Additional EDX spectra performed on single nanowires was used to determine the atomic percent of each element, as illustrated in Figure 7(b). Atomic composition from Figure 7(b) does not agree with the presence of $\mathrm{SiO}_{2}$ as the main component of the SiNWs and for this reason it could be assumed that the SiNWs are constituted by silicon partially oxidized.

As further evidence of the $\mathrm{SiO}_{x}$ composition of the nanowires, a chemical analysis of the components was performed by XPS on a sample composed of Au/carbon spheres/Si. For this XPS analysis, the nanowires were first dispersed in ethanol and deposited on a graphite (HOPG) substrate, in order to avoid the Si signal from the Si (100) substrate. Figure 8 shows the Si $2 p$ and O 1s core levels of silicon nanowires grown on carbon spheres/Si (100). The Si 2p peak is located at a binding energy of $103.4 \mathrm{eV}$ and the $\mathrm{O} 1 \mathrm{~s}$ peak at $532.3 \mathrm{eV}$, corresponding to the valence states of $\mathrm{Si}^{4+}$ and $\mathrm{O}^{2-}$, respectively, indicating that $\mathrm{Si}$ and $\mathrm{O}$ atoms should be as $\mathrm{SiO}_{2}$ [23]. Nevertheless, the above analysis of EDX spectra (Figure $7(\mathrm{a})$ ), taken directly on the SiNWs, indicates that not all the nanowire is completely oxidized.

\section{Conclusions}

We have synthesized silicon nanowires via a VLS mechanism with gold as catalyst by a thermal treatment process with no gaseous silicon source. The only silicon source is from the $\mathrm{Si}$ (100) wafer used as substrate. As innovation, we used silica and carbon microspheres as supporting materials for the growth of nanowires. The geometry of these structures allows 


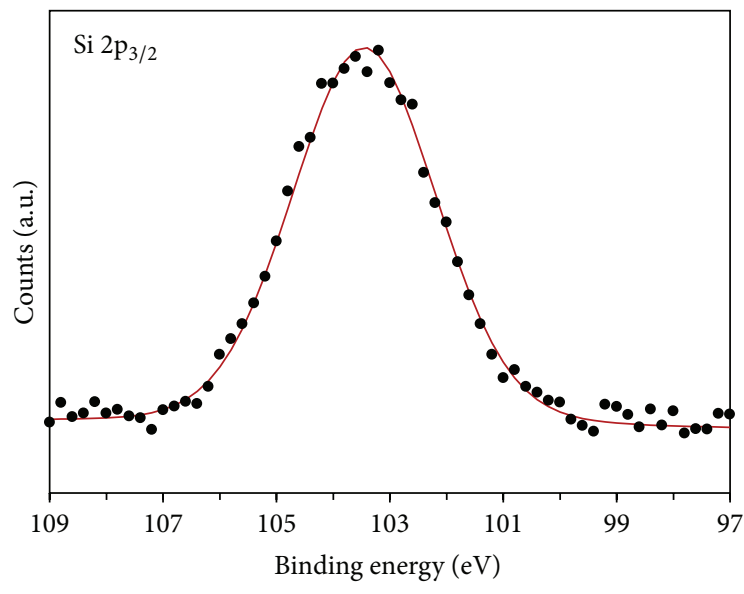

(a)

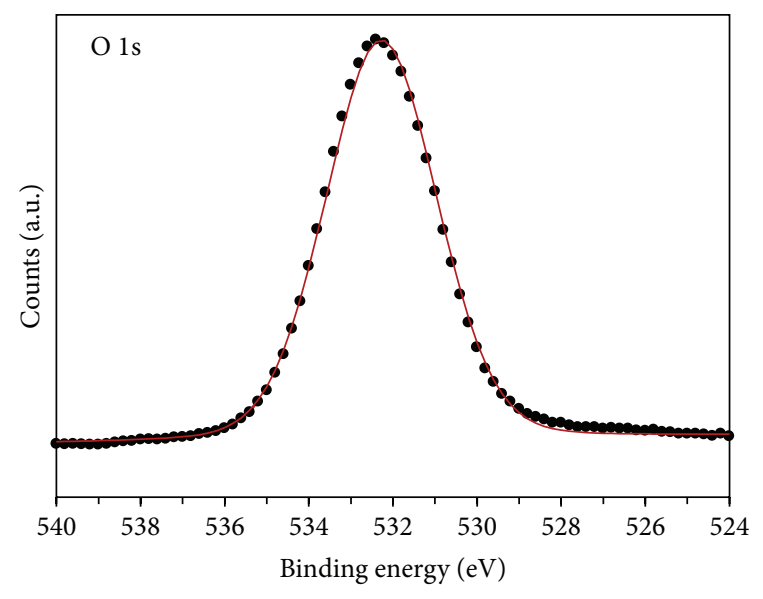

(b)

FIGURE 8: XPS spectra of silicon nanowires grown on carbon spheres/Si (100) and supported on a graphite (HOPG) substrate, (a) Si 2 $\mathrm{p}_{3 / 2}$ and (b) O 1 s peaks.

the layer of gold to give rise to a distribution of nanoparticles small enough for catalyzing the SiNWs growth, during the thermal treatment. The synthesized nanowires are compound of silicon oxide, having diameters of ca. $30 \mathrm{~nm}$ and lengths of several micrometers. An extensive analysis of the FESEM images revealed that microspheres with diameters lower than $1 \mu \mathrm{m}$ allowed a better control of the gold particles size, in addition to promote a higher density of nanowires.

In summary, it is noteworthy that the originality of this work lies in obtaining a material constituted by the microspheres with nanowires on their surface, which can be easily separated from the silicon substrate for their future use in multiple applications of energetic storage.

\section{Conflict of Interests}

The authors declare that there is no conflict of interests regarding the publication of this paper.

\section{Acknowledgments}

This work was supported by MICINN research Project MAT2010-19804. Financial support from the US Department of Energy through the Massie Chair project at University of Turabo is also acknowledged. The work of Arancha GómezMartínez was supported by the FPI fellowship from the Universidad Autónoma de Madrid. The authors thank I. Poveda for his technical assistance. The "Servicio Interdepartamental de Investigación (SIdI)" at Universidad Autónoma de Madrid and "Centro Nacional de Microscopía Español" (CNME) at Universidad Complutense de Madrid are also acknowledged.

\section{References}

[1] D. Disney and Z. J. Shen, "Review of silicon power semiconductor technologies for power supply on chip and power supply in package applications," IEEE Transactions on Power Electronics, vol. 28, no. 9, pp. 4168-4181, 2013.
[2] D. P. Yu, Q. L. Hang, Y. Ding et al., "Amorphous silica nanowires: intensive blue light emitters," Applied Physics Letters, vol. 73, no. 21, pp. 3076-3078, 1998.

[3] Y. Cui, Z. Zhong, D. Wang, W. U. Wang, and C. M. Lieber, "High performance silicon nanowire field effect transistors," Nano Letters, vol. 3, no. 2, pp. 149-152, 2003.

[4] Y. Paska and H. Haick, "Interactive effect of hysteresis and surface chemistry on gated silicon nanowire gas sensors," Acs Applied Materials \& Interfaces, vol. 4, no. 5, pp. 2604-2617, 2012.

[5] L. Touahir, S. Sam, A. Moraillon et al., "Functionalized silicon surfaces for biological and chemical sensors," Sensor Letters, vol. 8, no. 3, pp. 447-456, 2010.

[6] C. K. Chan, R. Ruffo, S. S. Hong, R. A. Huggins, and Y. Cui, "Structural and electrochemical study of the reaction of lithium with silicon nanowires," Journal of Power Sources, vol. 189, no. 1, pp. 34-39, 2009.

[7] R. Epur, M. Ramanathan, F. R. Beck, A. Manivannan, and P. N. Kumta, "Electrodeposition of amorphous silicon anode for lithium ion batteries," Materials Science and Engineering B, vol. 177, no. 14, pp. 1151-1156, 2012.

[8] H. Tzuen-Wei and F. C. N. Hong, "A reliable method to grow vertically-aligned silicon nanowires by a novel ramp-cooling process," Applied Surface Science, vol. 258, no. 20, pp. 79897996, 2012.

[9] L. Yu, B. O’Donnell, M. Foldyna, and P. Roca I Cabarrocas, "Radial junction amorphous silicon solar cells on PECVDgrown silicon nanowires," Nanotechnology, vol. 23, no. 19, Article ID 194011, 2012.

[10] R. Savu and E. Joanni, "Effect of processing conditions on the nucleation and growth of indium-tin-oxide nanowires made by pulsed laser ablation," Journal of Materials Science, vol. 43, no. 2, pp. 609-613, 2008.

[11] T. Hanrath and B. A. Korgel, "Supercritical fluid-liquid-solid (SFLS) synthesis of Si and Ge nanowires seeded by colloidal metal nanocrystals," Advanced Materials, vol. 15, no. 5, pp. 437440, 2003.

[12] J. J. Feng, P. X. Yan, R. F. Zhuo et al., "Ultrafast synthesis of Si nanowires by DC arc discharge method and morphology control," Journal of Alloys and Compounds, vol. 475, no. 1-2, pp. 551-554, 2009. 
[13] R. S. Wagner and W. C. Ellis, "Vapor-liquid-solid mechanism of crystal growth and its application to silicon," Transactions of the Metallurgical Society of AIME, vol. 233, no. 6, pp. 1053-1064, 1965.

[14] F. Márquez, C. Morant, V. López, F. Zamora, T. Campo, and E. Elizalde, "An alternative route for the synthesis of silicon nanowires via porous anodic alumina masks," Nanoscale Research Letters, vol. 6, article no. 495, pp. 1-7, 2011.

[15] D. P. Yu, Y. J. Xing, Q. L. Hang et al., "Controlled growth of oriented amorphous silicon nanowires via a solid-liquid-solid (SLS) mechanism," Physica E, vol. 9, no. 2, pp. 305-309, 2001.

[16] M. Paulose, O. K. Varghese, and C. A. Grimes, "Synthesis of gold-silica composite nanowires through solid-liquid-solid phase growth," Journal of Nanoscience and Nanotechnology, vol. 3, no. 4, pp. 341-346, 2003.

[17] D. Bahloul-Hourlier and P. Perrot, "Thermodynamics of the $\mathrm{Au}-\mathrm{Si}-\mathrm{O}$ system: application to the synthesis and growth of silicon-silicon dioxide nanowires," Journal of Phase Equilibria and Diffusion, vol. 28, no. 2, pp. 150-157, 2007.

[18] W. Stöber, A. Fink, and E. Bohn, "Controlled growth of monodisperse silica spheres in the micron size range," Journal of Colloid and Interface Science, vol. 26, no. 1, pp. 62-69, 1968.

[19] R. Roque-Malherbe and F. Marquez, "Synthesis and characterization of silica sphere-packing mesoporous materials," Surface and Interface Analysis, vol. 37, no. 4, pp. 393-397, 2005.

[20] Q. Wang, H. Li, L. Chen, and X. Huang, "Monodispersed hard carbon spherules with uniform nanopores," Carbon, vol. 39, no. 14, pp. 2211-2214, 2001.

[21] S. M. Prokes and S. Arnold, "Stress-driven formation of Si nanowires," Applied Physics Letters, vol. 86, no. 19, Article ID 193105, pp. 1-3, 2005.

[22] E. A. de Vasconcelos, F. R. P. dos Santos, E. F. da Silva Jr., and $\mathrm{H}$. Boudinov, "Nanowire growth on Si wafers by oxygen implantation and annealing," Applied Surface Science, vol. 252, no. 15, pp. 5572-5574, 2006.

[23] J. F. Moulder, W. F. Stickle, P. E. Sobol, and K. D. Bomben, Handbook of X-Ray Photoelectron Spectroscopy, Pekin Elmer Corporation, Eden Prairie, Minn, USA, 1992. 

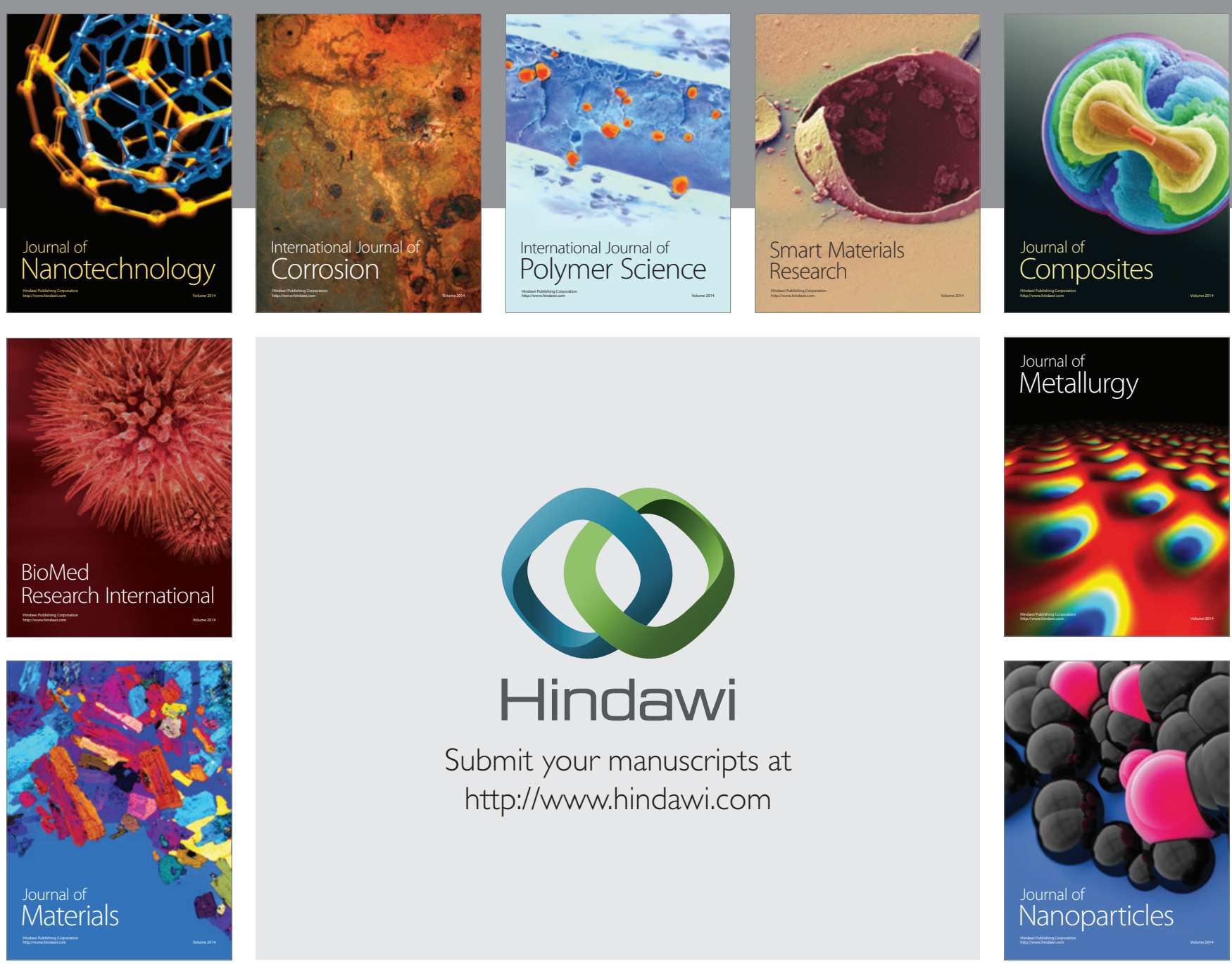

Submit your manuscripts at http://www.hindawi.com
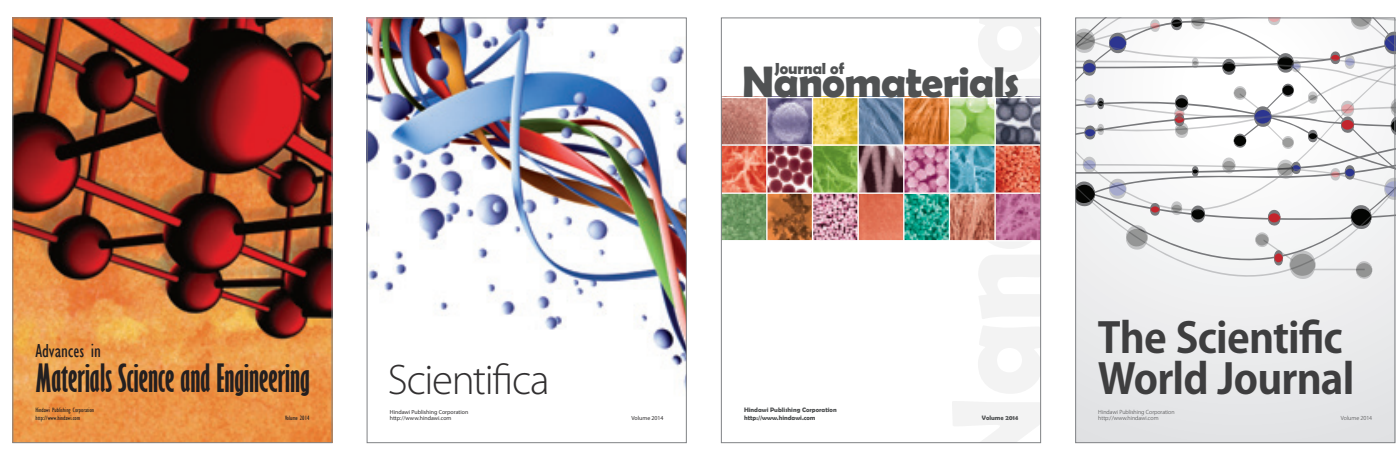

\section{The Scientific World Journal}
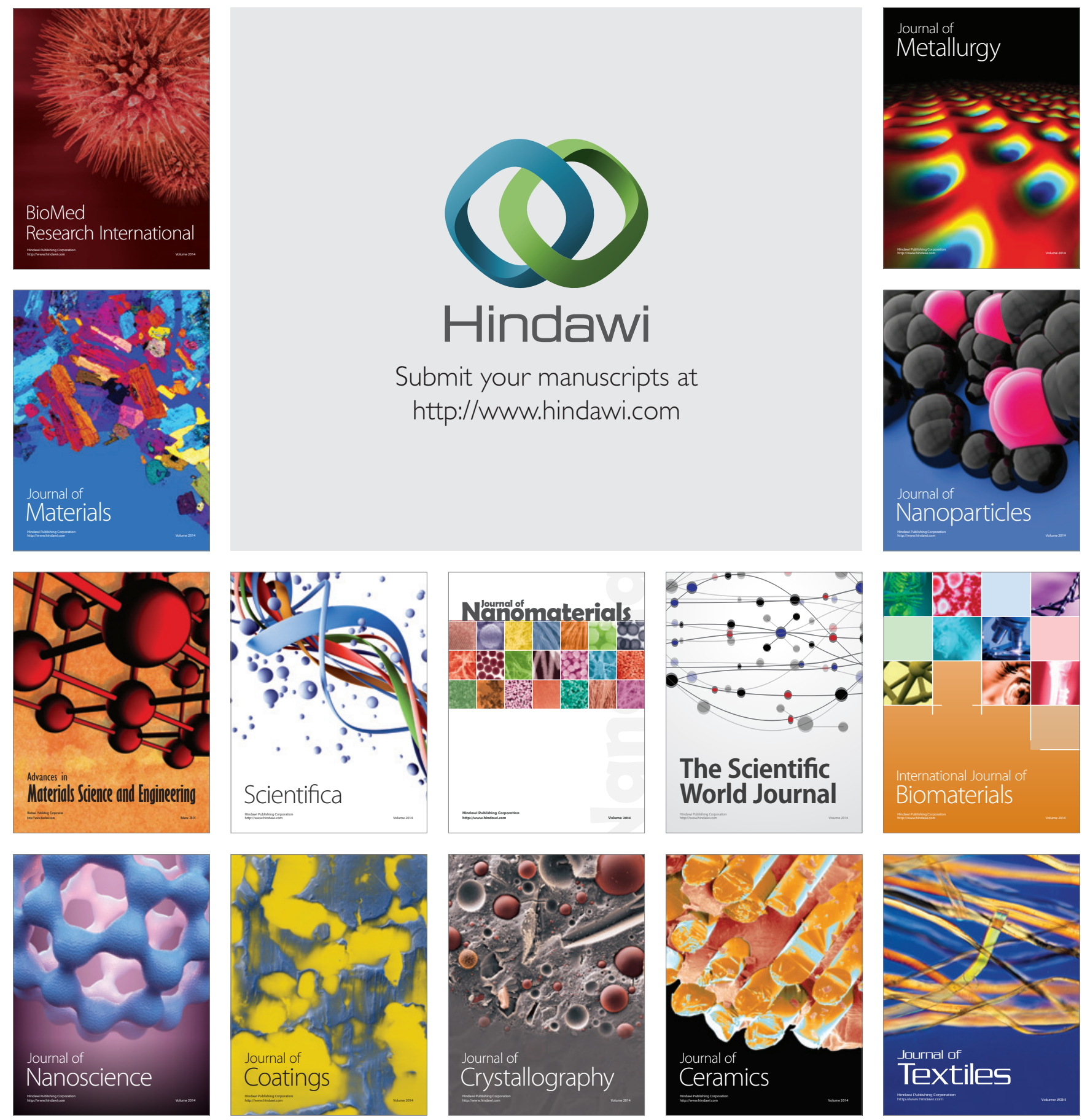